\title{
Study on Landscape Reconstruction of Traditional Rural Bazaar in the Process of Urbanization in China*
}

\author{
Yanhui SUI \\ Department of Biology and Chemical Engineering, Weihai Vocational College, Weihai, Shandong, China (rczhjxmw@163.com)
}

\begin{abstract}
Due to the quick urbanization in China, the modern commercial streets have gradually replaced the traditional business forms. Chinese traditional culture of rural bazaar is in danger and continues to disappear, which has resulted in immeasurable loss for the diversity of Chinese traditional culture. In this study, the protection of traditional rural bazaar in China was researched, our objective was to exposed how to reconstruct traditional bazaar cultural landscape in the process of urban ization, to study and summarized its features and functions, and to excavate its culture elements. Combined with modern urban construction, this study ascertained the value of the protection of cultural rural bazaar, explored the problems resulting from urbanization, and found out the communion point between the traditional bazaar culture and modern urbanization. The traditional rural bazaar culture was integrated into the modernization. The protection of traditional cultural and connotation of urban culture were enhanced in order to achieve the purpose of coordination with the modern urban landscape environment.
\end{abstract}

Keywords — bazaar, traditional culture, urbanization, landscape reconstruction

\section{城市化进程中传统乡村集市文化的景观重构研究}

\author{
隋艳晖 \\ 威海职业学院生物与化学工程系, 威海, 山东, 中国
}

摘 要 随着中国城市化进程的日益加快, 现代商业街逐步取代了乡村集市这一传统民俗商业形态, 中国传统文化正在并持续消 失中, 为我国传统文化的多样性造成了不可估量的损失。为此, 本文以传统集市为研究对象, 以传统集市文化在城市化进程中的景 观重构为探索目标, 对传统乡村集市进行考察并归纳总结乡村集市文化的特征与功能需求, 发掘民俗文化元素; 对传统集市文化进 行分析研究, 结合现代城市建设, 确定其文化的保护与传承价值; 探索城市背景下传统集市所面临的问题, 运用传统集市文化与现 代城市化建设的共融点, 将传统文化融入现代化建设, 在保护传统文化同时增强城市文化内涵, 达到与现代化城市景观环境相协调 的目的。

关键词 集市，民俗文化，城市化，景观重构

\section{1. 引言}

随着中国城市化进程的日益加快, 现代商业街逐步取 代了乡村集市这一传统民俗商业形态。尽管传统乡村集市 存在管理混乱、环境差等问题, 但作为我国农村居民延续 了几千年的风俗形式, 蕴含着独特的民俗文化, 值得加以 保护和传承。

在这一背景下, 如何通过景观设计的方法, 发掘传统 乡村集市的文化元素, 将这种民俗文化以一种新的形式融
入到现代化城市商业景观中, 使之更具艺术性、创意性, 具有重要的社会意义。不仅能够唤回城市居民对集市民俗 文化的记忆，而能够重塑城市景观特色。在保护传统文化 的同时增强城市文化内涵, 达到与现代化城市景观环境相 协调的目的。

*山东省自然科学青年基金项目支持（资助号：ZR2014EEQ026） 


\section{2. 传统乡村集市特征与文化内涵}

\section{1 集市的兴起与演变}

市, 即市场、集市之称。它指的是商品交换的场所, 由此衍生出 “市井”、“市肆”、“市㢆” 等称谓 ${ }^{[1]}$ 。上周时 期, 正式的市场已经存在, 并设置专门的管理机构; 春秋 时期, 国家经济带动了集市的发展; 战国至先秦时期, 许 多著名的大都市已形成; 汉代继承秦朝制度, 市得以继续 发展; 明代以后, 随着商品交换的日益频繁对于市场的需 求, 集市大量兴起。清代和民国时期的市场模式及格局基 本在明代时期已形成。

由于集市发展的地区差异, 集市的类型既存在统一性 又具有多样性。集市分类有多种形式, 按照集市的间隔时 间, 可以分为不定期集市、定期集市、常日市三种。按照 集市的性质, 则可分为特种集市和专业集市两种, 其中特 种集市包括庙会和集会。

\section{2 传统乡村集市}

乡村集市是指依据自然地域形式和沟通方便的原则形 成的、用以满足农民家庭正常贸易需求而在特定的时间和 地点开放的物品交换场所。施坚雅将其称为 “基层集镇” ${ }^{[2]}$ 。 乡村集市一般为定期, 规模较小, 主要进行商品交换, 为 买而卖的经营模式, 交易的品种主要是农副产品、当地手 工业品、土特产等。由于地域文化的不同，不同地区集市 形成了具有当地特色的文化景观。集市上处处体现出当地 人民的生活习俗, 如吆喝声、摊位设置以及遮荫、防雨工 具等。以威海市毕家疃集市为例: 集市以农历的四、九为 逢集日期, 即五日一集, 集市上的水果以当地的盛产的苹 果、梨、柿子、无花果以及相应的加工产品为主, 集市随 处可见鱼、虾、海带等海产品以及各类海产品制成品。商 贩以当地人为主, 操着浓厚的胶东口音叫卖。由于威海为 沿海城市, 夏季高温多雨, 紫外线较强, 因此在夏天随处 可见戴一种全遮挡型防晒帽的当地人, 这也成为当地一道 具有沿海特色的人文景观。

乡村集市用地的灵活性较强, 在不开市时间自行解散 不影响村镇村民生活, 在开市时四周商贩聚集在一个固定 的村镇, 形成商业街, 为附近村民提供日常生活必需品, 大大提高了土地的利用率。由于乡间集市活动, 促进了单 个家庭、散落村落的联系, 从而形成了以集市为中心的活 动集体。

\section{3. 传统乡村集市的景观文化价值}

3.1 传统乡村集市的景观特征

1）集市选址的合理性

通过对威海市以及德州市的乡村集市的调查与分析发 现：乡村集市的数量与地区人口密度成正比; 为方便周围 商贩、村民的活动，乡村集市一般设在交通路线易于达到 的村镇。一般在方圆 10 公里内至少有一个集市, 以满足当 地村民日常生活物质需求。

2) 集市摊位的形态特征

组成集市的摊位为当地人的日常的生活生产用品, 简 便、易于携带。简单几个铁支架和农民盖蔬菜常用的蒲苇 席, 穿插在一起足可以应付买卖的空间需要, 摊位可以根 据需求任意移动, 收放自如。推位有的一个接一个像一条 条长龙, 有的散落在其中, 这都成为集市特有的景观。日 常没有集市时推位还可以拆掉用作其他支撑、遮盖等用途, 同时实现了资源的最大化利用。

\section{2 乡村集市的文化的载体作用}

将在山东农村地区，年前的几个大集热闹非凡，赶集 成了村民之间的问候语，“二十三赶集去呗”、“赶集走”、 “赶集买年货” 等。过年期间的贴的春联、年画、吃的蔬 菜、放的鞭炮、穿的新衣等等, 都需要赶集去买。集上商 贩的吆喝声、村民的讨价还价声充斥着整个集市，摊位一 个接一个，摊靠摊、人挤人，已成为一种传统民间活动， 给人传递一种过年的信息。集市上的物品无不暗藏着特定 的文化特质，将各个相近的文化特质综合起来构成文化从 ${ }^{[3]}$ 。

传统的民俗娱乐活动一一扭秧歌也在集市上进行。在 山东省农村地区, 每到过年过节都有秧歌的习俗。例如山 东省乐陵县的农村, 每年大年初一到正月十五都会组织种 歌, 村民每天吃完午饭、晚饭后以锣声为信号聚集在村子 的空地上进行练习。待到正月十五之后二十的每个逢市日 期，集市周围各个村子的秧歌队伍就会在集市上进行汇报 演出, 村民闻讯赶来，集市作为一个娱乐场所，成为了秩 歌的传递媒介。农民在集市上的接触也成为了一种文化交 流方式, 另外, 农民的购物行为也可看作为一种文化行为, 乡村集市以独特地形式，形成了购物、文化、交流的多重 空间。

总而言之，乡村集市在农民的生活生产中占有不可替 代的地位, 乡村集市几乎承载了农民以自给自足为生活方 式的所有因素。 


\section{3 传统乡村集市在城市文化结构中的作用}

在社会快速发展的过程中, 城中村成为了城市化进程 中特有产物, 集市作为典型的代表被遗留了下来。例如在 杭州文一、文三路之间的近一公里的主干道两侧, 逐渐发 展成为专门为附近大专院校学生销售生活用品、服装等日 用小百货的夜市。同样的还有原西湖边的夜市及现在吴山 路上的夜市。

1）乡村集市承载了一座城市的记忆。

由于地理位置、风土人情的不同, 每个城市有着属于 自己的历史, 集市是历史的产物, 是地域文化的重要组成 部分, 尤其是见证城市发展的老一辈对集市有着特殊的感 情与记忆, 如若将集市贸然取缔, 消失的不仅仅是集市, 而是老一辈的回忆和生活习性。城市失去了原有的地方特 色，因此削弱了城市的文化底蕴。

2）乡村集市的地域文化的代表性。

集市上有很多面临淘汰却不太旧的商品和低价商品, 小商贩的叫卖声充满特色, 张乃坚在《我当京城赶集族》 对一个小伙的叫卖声描述到 “万里长城永不倒, 就数我的 袜子好! 别不破, 剪不断, 五元四双真合算!五元钱, 花不 穷, 攒不富, 再攒也成不了万元户!人之初, 性本善, 坑 人的买卖咱不干...$”$ ” 从叫卖声中感受到商贩的质朴纯真, 在交易过程中充满乐趣与人情味, 都体现出一个城市的本 土文化。

研究城市文化的学者认为, 集市与生活空间、城市文 化、人民的想象力和创意产业有着千丝万缕的联系。集市 成本低、流通性大, 能满足许多人的生意梦, 若集市能吸 引新的元素, 将艺术与生活融合, 从而可丰富一个城市的 文化。

\section{4. 问题与分析}

城市化是经济发展的必经之路, 随着城市化建设的不 断加快, 集市也在被不断的改造。在这一过程中, 城市化 与集市之间总是存在着某种冲击, 以至于给人们一种集市 与城市不协调的错觉。

\section{1 城市化对集市的影响}

通过调研发现城市化对集市的影响主要分为以下几点 问题:

1) 城市化结构趋于相同, 对原有农村地区地理环境、 人文地貌等特色不进行任何考察了解的情况下, 对地区进 行统一规划、统一建设, 虽城市环境得到改善, 但传统地 域特色遭到严重破坏, 乡村集市作为 “受害者”之一, 城 市化对其存亡已构成严重威胁。
2) 城市化的规划加入了浓重的城市色彩, 地区丧失了 原有的地域文化特色, 削弱了地域的文化内涵, 对城市的 文化结构产生了负面影响。

3) 城市化间接性的对城市居民结构产生了影响。集市 被硬性取消，造成以 “赶集” 为主要收入的商贩经济收入 受到威胁, 生活无法得到障, 迫使商贩改行从事其他职业, 因此造成城市人口结构改变。

\section{2 集市对城市的影响}

问题的存在往往具有两面性, 城市化对集市的存在构 成威胁, 乡村集市也对城市化社会环境产生了负面影响:

1) 集市贸易的进行给城市的交通秩序造成了严重的负 担。每逢赶集, 交通堵塞, 给周围居民尤其是上班族的出 行带来不便。如在一篇关于集市的报道《传统民俗与现代 城市的碰撞夹缝中的集市》中描述到: “清晨不到 7 点, 许 多贩卖蔬菜瓜果的商贩已经 “上集”。上午 9 点左右, 道路 交汇处的交通信号灯已经失去作用，无论骑车的市民还是 开车的市民都只能在人流中艰难穿行。”成为城市管理的难 点, 集市对现代城市管理规划的负面作用难以避免。

2) 集市给城市带来了脏乱差的环境, 严重影响了城市 面貌。集市结束后会遗留大量垃圾, 加重了环卫工人的负 担，处理不及时，会遭到周围居民的投诉。

3) 噪音影响。城中集市多在大早就开市, 由于集市经 营模式的特殊性，交易多伴随叫卖声，对周围的居民的作 息造成了严重的困扰。

\section{3 市民对集市的态度分析与解决途径}

综合以上因素, 可以看出集市的去留问题已形成了对 立两派。

支持者包括城市中的退休老工人、集市商贩、附近部 分居民。老集市里存在着几代人的记忆; 以赶集作为经济 收入来维系正常生活; 集市蔬菜水果等价格便宜, 这些都 成为集市维系下去的重要因素。反对者主要为上班族、城 管人员和环卫工人。反对原因是集市给城市造成了脏乱差 的环境, 影响城市面貌、造成交通堵塞、城市管理困难等 问题。

无论是城市化的进程威胁到集市的存在，还是集市的 存在影响了城市化经进程, 集市作为中国文明的发展的产 物, 有一定的保护价值。若将中国传统乡村集市文化合理 应用于现代城市结构中，既能避免集市在城市建设中被取 缔损毁的危险, 又能解决集市与城市生活格格不入的局面, 即同时提供了历史传统文化的和现代化利用的两难问题的 解决方法。 


\section{5. 乡村集市文化景观重构的主要模式}

\section{1 中国传统乡村集市的景观结构分析}

集市是中国传统生活方式的重要组成部分之一, 有着 悠久的历史, 在乡土社会扮演多种角色, 集市的发生、发 展也处处体现 “和谐” 这一中华传统美德。集市在发展与 演变的过程中, 集各朝代的历史、文化、传统习俗与一体, 有极高景观、科学、人文研究价值。如今乡村集市的发展 在城市化的过程中正趋于灭亡, 集市在城市结构中的重新 定位是决定传统乡村集市文化景观能否沿可持续性发展道 路延续下去的关键所在。

1）人文景观结构

在思想上改变居民对传统集市文化的认识, 培养将传 统乡村集市融入城市文化中, 给传统的乡村集市在城市建 设发展中重新定位。城市的发展改变了居民的生活消费观， 集市作为落后的消费形式被新一代居民抛弃、遗忘, 集市 的维持也仅靠老一辈对原有生活的滕恋、记忆来支撑, 加 上城市建设者对城市历史、地方习俗的认识程度的欠缺, 集市在城市中的位置被逐渐取缔, 导致原有城市具有特色 的生活方式、传统习俗等无法体现。原有居民的生活习惯、 风土人情都是集市文化的重要组成部分, 是传统乡村集市 文化在现代城市能否扎根发展的关键所在。

2) 集市的形态

传统乡村集市的摊位设施、交易物品等都与当地原住 居民的生活习俗习惯息息相关; 集市没有严格的空间限制, 商贩可按照自己需求扩大、加宽推位, 方便挪动、易于拆 卸组装。集市的改造应在保留集市传统民俗元素的前提下， 结合集市摊位的便捷性, 改变整个集市摊位散乱的形式, 实现传统乡村集市的形态与现代性商业形式的创造性结 合。

\section{2 传统乡村集市文化的景观重构方法探索}

现代化商业形式与传统集市的创意性结合一一城市化 进程加快, 新型的商业建筑、消费模式在居民的消费理念 中逐渐上升到主导地位, 而传统集市在城市建设、居民记 忆中慢慢淡化。提取传统乡村集市的主要元素, 与现代商 业建筑、经营模式创意性的结合才能实现乡村集市文化在
城市景观中重构的目的。具体措施包括:

1) 元素提取, 唤起记忆。通过对当地乡村以及传统本 土文化元素的提取, 利用现代设计手法进行解构、重组、 夸大等, 在景观中给予充分体现, 增强原有村民对场所的 认同感，唤起对传统集市的记忆。

2) 合理区划, 满足功能。集市的功能分为两部分, 集 市期间主要满足买卖的商业功能, 既要为卖方提供摊位, 也要为买方提供交通，同时做到商品的分类布局，便于有 序管理。其他大部分时间的非集市期, 主要满足交通功能, 通过景观设计亦可实现充当市民交往和休闲空间。要实现 这一目标，场所感的塑造最为关键。

\section{6. 结语}

城市化进程的加快以及缺少对传统集市文化的保护意 识, 导致乡村集市数量的急剧下降, 仅存为数不多的传统 乡村集市也面临着被取缔甚至完全消失的危险。就如何将 民俗文化以一种新的形式融入到现代化城市商业景观中的 问题, 提出传统文化在现代城市文化建设中的重要性, 通 过探索传统乡村集市的特征和文化内涵，从而确定乡村集 市文化的保护方式。充分利用当地景观因素，合理协调城 市景观结构与传统文化、地域人脉、人文习惯的关系，建 设有民族特色城市文化结构与现代化城市发展的关键所 在。因此, 当前首要任务在于寻找科学合理的方法, 来解 决保护传统文化的同时增强城市文化内涵的难题，使之与 现代化城市景观环境相协调。

\section{参考文献(References)}

[1] Pan Shuzhi. Cities and towns in Jiangnan: Changes of tradition. Shanghai: Fudan University Press, 2005.

[2] Shi Jianyun, Xu Xiuli. Market and social structure in Chinese rural. Beijing: Chinese Social Science and Literature Press, 1998.

[3] Wang Jing. Bazaar culture in the process of modernization based on field investigation of L Town in Hebei Province. Journal of Higher Correspondence Education (Philosophy and Social Sciences), 2011, 24 (12): 28-30. 